\title{
Knowledge Applications for Life Events: How the Dutch Government Informs the Public about Rights and Duties in the Netherlands
}

\author{
Ronald Heller and Freek van Teeseling \\ Be Informed, Linie 620, 7325 DZ Apeldoorn, Netherlands \\ \{R.Heller, F.vanTeeseling\} @beinformed.nl
}

\begin{abstract}
The Dutch government has several ontology driven applications on the internet that inform the public about rights and duties that are relevant for certain life events. Life events such as "New to Holland", "The death of a close relative" and "Working and studying" are examples of events in life where you want to be informed about your rights and duties. In the demonstration we show how we make use of an ontology to determine a profile of the user and how we give him or her the information that is tailored to his/her specific situation.
\end{abstract}

Keywords: Profile, ontology, life events, government, knowledge-models, customer oriented.

\section{Background and Application Context}

Citizens demand better support and service from the government than ever before. The world has become more and more complex and citizens demand that governmental organizations adapt to this ever-changing world more quickly. Agility is no longer just wanted or needed, it is crucial. Citizens see the government as one big organization from their viewpoint, although it is actually a huge complex of tasks and responsibilities, divided over many different smaller organizations. This results in the fact that many means are used to inform citizens about all kind of laws and regulations, e.g. the internet, brochures, commercials etc. The main problem is that citizens are unable to receive a complete overview of all the relevant information. This is why they ask the government for one clear answer with regards to which regulation they must comply to. They don't care which organization is involved. Politicians in the Netherlands have acknowledged this and strive for a more agile and efficient government. In the specific case of the Netherlands, this means that over 1300 governmental organizations are asked to change their way of serving and informing the public. At the moment most information and services are offered to the customers from a supplier point of view. The Dutch government intends to change this into a citizen-centric approach. Dutch governmental organizations are now working together towards a better customer interaction. They identified so called life events that are important for citizens. Examples of such life events are the death of a close relative [7] or the immigration into the Netherlands [4]. The important factor should be the situation and information status of the 
citizen, not the product or service of the individual governmental organization. Several governmental organizations are now working together to be able to inform a citizen when needed and with exactly the information needed.

\section{Demonstration}

The demonstration covers one life event: New to Holland [5]. It is an application giving background information for people who want to migrate to the Netherlands. Twelve organizations were involved in the development of this application, such as the Immigration office, organizations for taxes, grants and more. When you want to come to the Netherlands as a student you will need other information compared to when you want to work or live or even come to the Netherlands as an "Au pair". The demo will show how the personal situation of the customer is identified. An ontology is used for this profiling, and from this the ontology is used to decide on the relevant information. A WYSIWYG technique is used to create and store the knowledge models. There is no separation between model and implementation. A visual graph with subject-relation-object triples can be seen in the screenshot in figure 2. The customization to a specific application as New to Holland is essentially done by setting up an appropriate metamodel and the definition of patterns and guidelines necessary for the application [2].

In the case of live events this means that the governmental organizations are able to change the ontology by modeling the triples themselves using the graphical modeling environment. The tool supports an easy way of specifying which piece of information is relevant for certain citizens using strong typed relations between concepts.

The demonstration will show the application, including the ontologies it is based on. In the demonstration we will also discuss the process of development, aspects of maintenance using ontologies and the reuse of models over ontologies and applications.

\section{Profiling Using Ontologies}

In order to be able to make consistent knowledge models that can be managed and maintained by the information owners (business users), we defined a metamodel based on the Be informed methodology [2].

\subsection{The Metamodel}

The metamodel for the life event is far from complex. It consists of three layers: profile, advice and descriptions and annotations.

First we identify the profile of the customer, and following this it is determined which advices should be offered. The relevance of each piece of advice is dependent on the situation of the customer. One of the most important factors is the reason of his of her stay in the Netherlands (work, study, living). Other factors are also important, like the age of the customer and the nationality. The relevant advices are then linked to pieces of information to be shown with that advice (Description and annotations). Adding this layer also enables us to provide the information multi-lingual. In this case Dutch and English. This metamodel is used for all "Life Event"Applications. 
Labels:

-Name[NL]

-Name [EN]

-Fullname[NL]

•Fullname[EN]

-Quationlabel[EN]

-Questionlabel[NL]

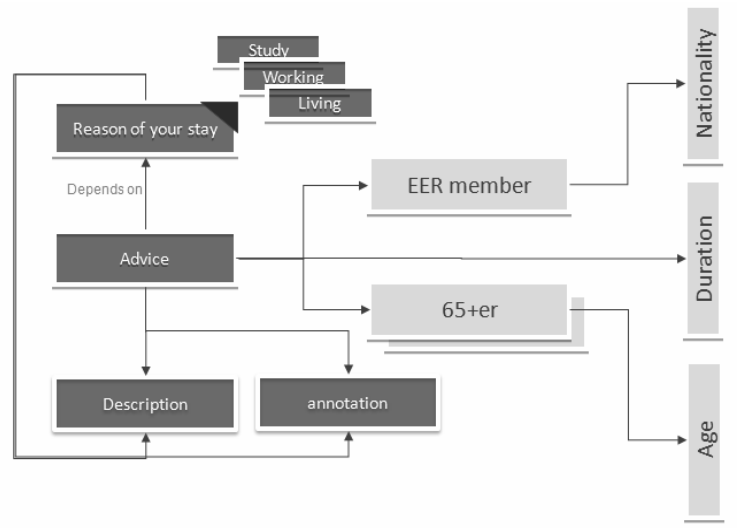

Fig. 1. The metamodel

\subsection{Modeling the Advice}

The involved organizations came up with roughly a hundred different pieces of information that they thought were of any interest to the public. All that had to be done was stating when these pieces where relevant, using the metamodel as mentioned above. This metamodel allows to select among a set of goals and purposes for people to immigrate to the Netherlands (working, studying, asylum, working as an "Au pair" etc.) in interaction with the user and dynamically. The metamodel in essence specifies which are the relevant questions to ask to decide dynamically on the purpose for the immigration and proceed accordingly. This resulted in knowledge models like shown in figure 2.

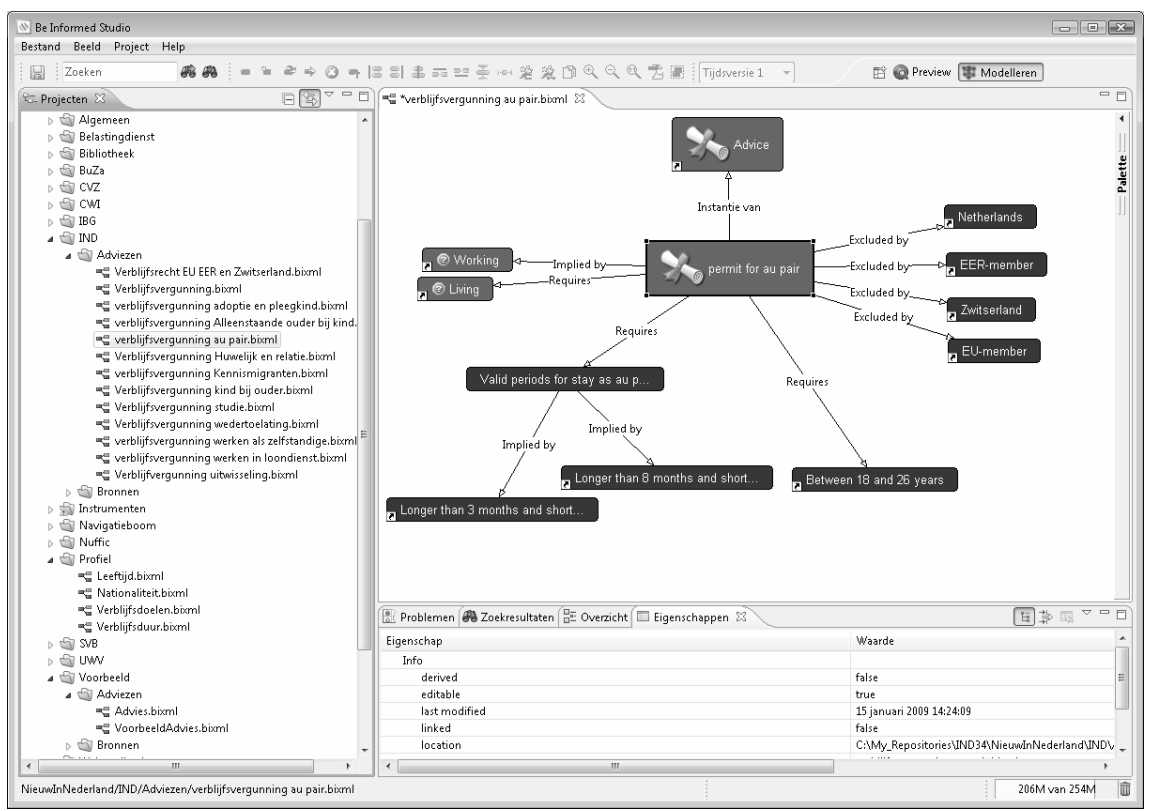

Fig. 2. Knowledge model example 
In the example "Permit for Au Pair" is a concept of type Advice, triggered by purposes combined with length of stay, nationality and age. Reuse of knowledge is key to knowledge management, so knowledge about nationalities is reused where needed. In the model above the deducted concept of EU-membership is important for inferring the au pair advice, and is reused in different deductions.

\section{Life Events on the Internet}

On the web one can currently find several life event applications. Go to http://www. overheid.nl [5] to find the most up to date list. The demonstration will mainly cover the New to Holland application.

\subsection{New to Holland}

In the application a personal checklist is the actual profile that we use to infer which pieces of information are relevant for the customer. The left screenshot shows the start interface for the users. The right screenshot shows the inferred result. Again this is rather a simple screen where users can read relevant information, that applies to that specific profile. The application uses the power and possibilities of an ontology which remains in the background and opaque to the user. It does however offer easy use in managing and maintaining the knowledge involved using the Studio environment from figure 2 .

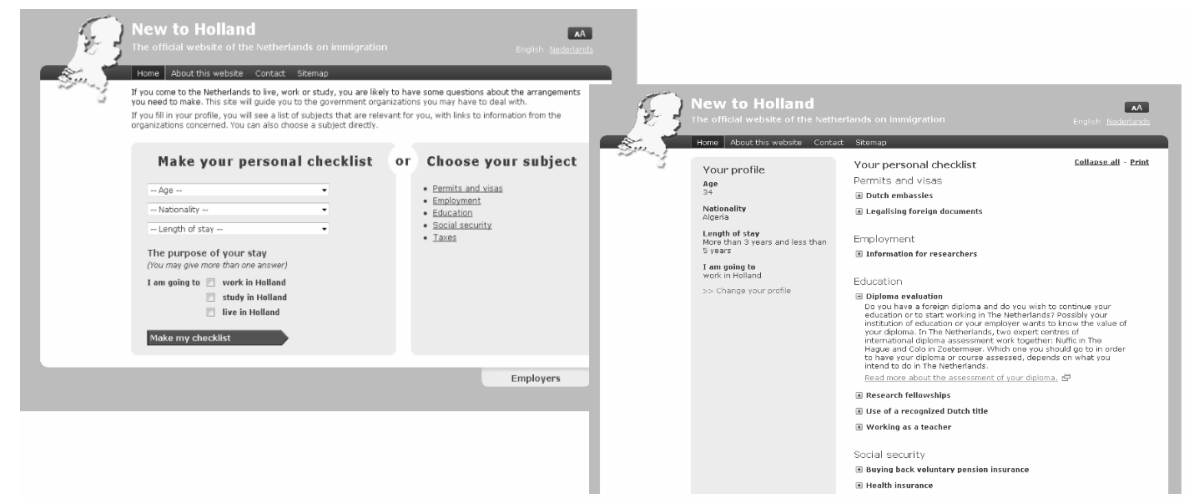

Fig. 3. New to Holland website

\section{References}

1. Verbeek, J., Rensen, G.: A Citizen Centric Government Enabled by Semantic Technologies. In: Semantic Technology Conference, May 18-22, San Jose, CA (2008)

2. Van Teeseling, F., Heller, R.: Patterns in Metamodelling. Be Informed White paper (2008)

3. http://www. newtoholland.nl 
4. http://www arbeidsmigratie.nl

5. http://www. overheid.nl

6. http://onderwijsenbijverdienen. overheid.nl

7. http://www. vertreknaarhetbuitenland. overheid.nl

8. http://www. overlijden-overheid.nl 